\title{
Synthesis and Characterization of Biodegradable Film Chitosan and Carboxymethyl Chitosan to Substitute Silver Wound Healer Plaster
}

\author{
AMRI SETYAWATI ${ }^{*}$, INDRIANA KARTINI ${ }^{2}$, DENI PRANOWO², \\ LISNA JUNAENI MUIZ ${ }^{3}$ and SYAFITRI HASYATI ${ }^{2}$
}

\begin{abstract}
${ }^{1}$ Chemistry Study Program, Islamic University of Indonesia, Yogyakarta, Indonesia. ${ }^{2}$ Chemistry Department, Universitas Gadjah Mada, Yogyakarta, Indonesia. ${ }^{3}$ Chemistry Department, Universitas Matha'ul Anwar, Banten, Indonesia.

${ }^{*}$ Corresponding author E-mail: amrisetyawati@uii.ac.id
\end{abstract}

http://dx.doi.org/10.13005/ojc/330637

(Received: September 28, 2017; Accepted: October 20, 2017)

\begin{abstract}
Currently, wound dressing is made of fabric or polyvinyl chloride (PVC) plastics with silver as active ingredients. Residues of silver can be toxic in the environment and PVC waste is a very long decomposed by soil. Chitosan and carboxymethyl chitosan (CMC) film have been synthesized as a biodegradable material that potential to replace silver wound plasters. CMC film has been synthesized from chitosan with a wide range of molecular weight. Chitosan with high molecular weight resulting from the reflux (1a) while the low molecular weight chitosan produced from microwaves assisted organic synthesis-MAOS (1b). All chitosan and CMC are then molded into a film chitosan and $\mathrm{CMC}$ and their properties were analyzed by solubility test. The $\mathrm{COOH}$ number of the $\mathrm{CMC}$ is also measured by titration. The results show that the CMC were synthesized from chitosan MAOS (2b) has higher $\mathrm{COOH}$ group than $\mathrm{CMC}$ from chitosan reflux (2a). Chitosan with MAOS process is able to produce a more homogeneous and has a lower molecular weight in a short time. Chitosan $1 \mathrm{a}$ films are strong and rigid while chitosan films $1 \mathrm{~b}$ and $\mathrm{CMC}$ films have fragile nature. Test of solubility in physiological solution showed that the CMC films lost $78.56 \%$ Massa while chitosan films 1 a only $44.59 \%$. This show that a combination of chitosan films for wound plaster with CMC films as a wound healer active ingredient is suitable for replacing the fabric wound plasters contains silver as an active ingredient.
\end{abstract}

Keyword: Chitosan, Carboxymethyl chitosan, Film, Wound healer.

\section{INTRODUCTION}

A skin injury is generally requires cover from being infected by bacteria or pathogens abundant in dust and air ${ }^{1,2}$. In fact, many types of bacteria that live on human skin can make infection ${ }^{3}$. Currently, the plaster dressing's products made from PVC material that is difficult to decompose with the silver embedded fabric as an active ingredient and material polyvinyl chloride used as an adhesive. 
Residues of silver can be toxic in the environment. PVC, fabrics and plastics plaster can also pollute the soil because it takes a long time to degrade.

Chitosan and carboxymethyl chitosan is reported as a potential wound healer polymer ${ }^{3,4}$ and also biodegradable. Substitution of toxic active ingredients such as silver with chitosan and its derivatives are expected to reduce environmental pollution. If this material developed into wound plaster, its ability to inhibit bacterial growth can prevent infection in wounds.

One of the chitosan derivatives is carboxymethyl chitosan. Chitosan is a non-soluble compound in water and only soluble in certain organic solvents in acid conditions ${ }^{5,6}$. This led to the limitation use of chitosan to be directly applied. Otherwise, carboxymethyl chitosan is water-soluble and showed lower toxicity than chitosan. Carboxymethyl chitosan is a chemical compound that is more stable, water soluble, biodegradable, biocompatible, and non-toxic than unmodified chitosan $^{7,8}$. Carboxymethyl chitosan also has more active site than chitosan that can be more potential as antibacterial agents and pathogens ${ }^{9}$.

Anti-microbial activity of chitosan and carboxymethyl chitosan make this compound widely applied in agricultures to inhibit the growth of fungi and bacteria during storage of vegetables and fruits ${ }^{10}$. Because of these polymers have a very low toxicity and safe if absorbed body, this application is widely used, especially in the food and medical industries. Conversely, chitosan is not widely used as anti-microbial agents in the food industry and health because it can change the color and smell ${ }^{10}$. In addition, carboxymethyl chitosan can also be applied to the environment that is made as membranes or adsorbent for wastewater treatment ${ }^{11}$. Other applications of carboxymethyl chitosan in the medicals and pharmaceuticals are used to control the release of drug compounds, wound healing and nerve repair cartilage ${ }^{1213}$.

Carboxymethyl chitosan effects as a wound healing agent are reported by some researcher. Carboxymethyl chitosan can stimulate the proliferation ${ }^{9}$ and collagen secretion of normal skin and keloid fibroblasts ${ }^{14,15}$. This is very useful for accelerating wound healer. A water-soluble derivative of chitin and chitosan even reported improving skin sores, nerve, cartilage, and bones $^{16,17}$.

Some researchers have reported the benefits of chitosan for various purposes including wound repair ${ }^{3,18-20}$. Various methods of organic synthesis have also been widely reported. But the relations of molecular weight to the number of $\mathrm{COOH}$ group's and bio-solubility of CMC no one has studied. Whereas the number of $\mathrm{COOH}$ groups should be very important to investigate because it deals with anti-bacterial properties owned chitosan and its derivatives. In this present study, it has been conducted a synthesis of chitosan with reflux and microwave radiation technique which is then synthesized into CMC and molded into the plaster. Then the relation of material chitosan with a number of $\mathrm{COOH}$ formed is observed, also it solubility in physiological solution and their physical appearance.

\section{MATERIALS AND METHODS}

All material used is from E.Merck with pro analysis (p.a) quality i.e mono chloroacetate, potassium hydroxide, isopropanol, ethanol, and calcium acetate. Infrared spectra were recorded with a Shimadzu Prestige-21 FTIR spectrometer using $\mathrm{KBr}$ disc.

\section{Synthesis of CMC}

This process is done by the direct alkylating methods wich is $\mathrm{N}$, O-Carboxymethyl chitosan as the target molecule. About $0.5 \mathrm{~g}$ chitosan powder with various molecular weights from reflux and MAOS at various watt and time was added by 11 $\mathrm{mL}$ isopropanol in Beaker glass and stirred for 20 minutes. After that, please added $4 \mathrm{~mL} \mathrm{NaOH} 40 \%$ $\mathrm{b} / \mathrm{v}$ drop wise at $50^{\circ} \mathrm{C}$, and followed by $1 \mathrm{M}$ mono chloroacetate in isopropanol. Stand the reaction in stirrer condition at $50^{\circ} \mathrm{C}$ for 20 hours and then end with adding the reaction mixture with ethanol $70 \%$. The precipitated product was filtered, washed with ethanol and dried in an oven at $45^{\circ} \mathrm{C}$.

\section{Determine the carboxylic acid groups}

An amount of $100 \mathrm{mg}$ carboxymethyl chitosan in the Erlenmeyer flask was added by 10 $\mathrm{mL}$ calcium acetate $0.5 \mathrm{M}$ and $40 \mathrm{~mL}$ distilled water. The blank standard also prepares by this solution 
without carboxymethyl chitosan. The sample and standard solution were shaken for $24 \mathrm{~h}$, and then the precipitate formed was filtered and washed with $10 \mathrm{~mL}$ distilled water. The filtrate is collected and then titrated with $0.1 \mathrm{M} \mathrm{NaOH}$ solution with $\mathrm{pp}$ indicator until the color changes to pink. The results obtained are then calculated by the equation proposed by Stevenson (1994).

$$
-\mathrm{COOH}=\frac{(\mathrm{Vs}-\mathrm{Vb}) \mathrm{N} \times 10^{5}}{\text { Berat sampel }(\mathrm{mg})}
$$

$\mathrm{Vs}$ and $\mathrm{Vb}$ are the volumes of a standard alkaline solution used for titrating the sample solution and the blank, and $\mathrm{N}$ is the normality of a standard alkaline solution.

\section{Film forming and solubility test}

A total of $1 \%(\mathrm{w} / \mathrm{v})$ chitosan from reflux and microwave was dissolved in a solution of acetic acid $1 \% \mathrm{v} / \mathrm{v}$ and placed in a petri dish. It is left to dry at $60^{\circ} \mathrm{C}$ to form a thin layer. Then, $3 \mathrm{M}$ of $\mathrm{NaOH}$ is added in to be able to remove the thin layer from the petri dish. A thin layer is then washed with

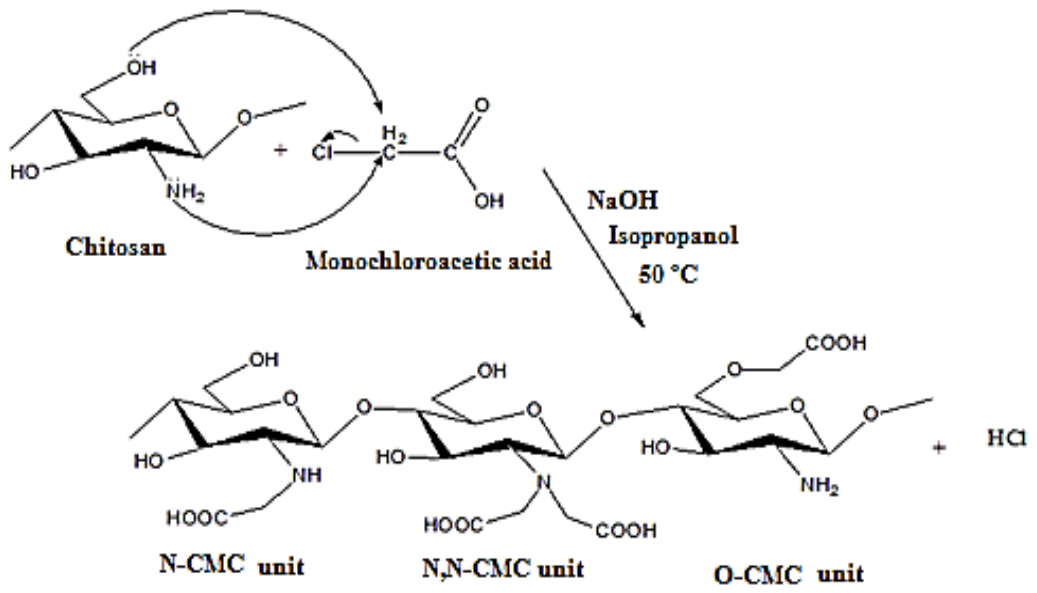

Fig. 1: Scheme of carboxymethyl chitosan synthesis

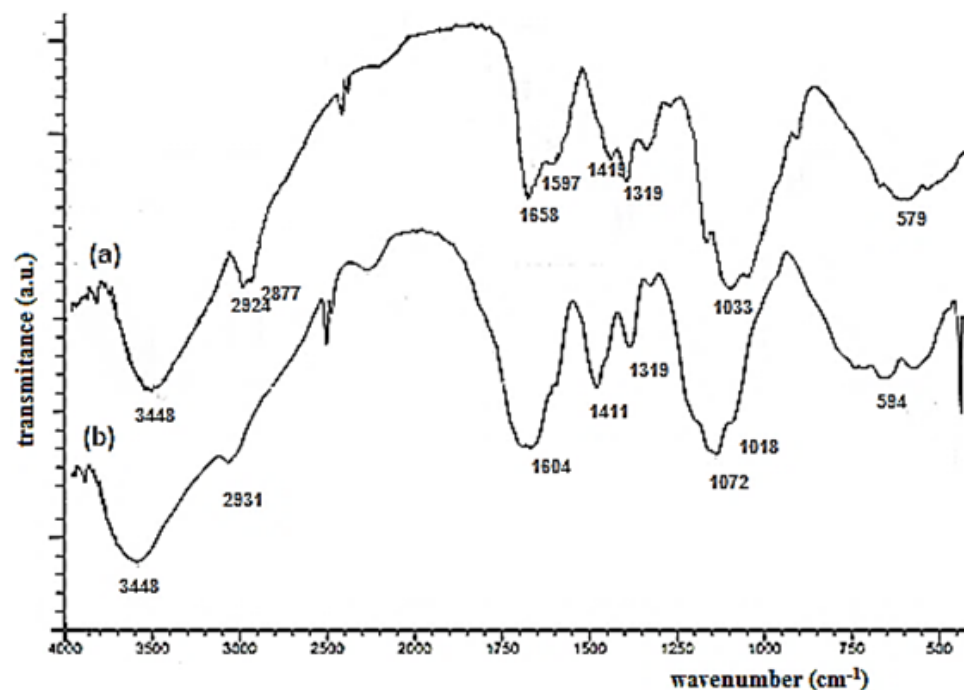

Fig. 2: FTIR spectra of chitosan (a) and Carboxymethyl chitosan (b) 
distilled water until neutral and wind dried. Meanwhile, to make a thin layer of carboxymethyl chitosan does not need to be dissolved in an acid solution. One percent of carboxymethyl chitosan solution $(\mathrm{w} / \mathrm{v})$ in distilled water were placed in a polystyrene petri dish and then allowed to dry at $60^{\circ} \mathrm{C}$.

Solubility test of chitosan and carboxymethyl chitosan films is done by the method Wongpanit et al (2011). The film with a particular initial weight, soaked in a solution of physiological $0.1 \% \mathrm{NaCl} \mathrm{w} / \mathrm{v}$ for 48 hours at $37^{\circ} \mathrm{C}$. the solubility of the film is calculated from the amount of weight lost after soaking according to the equation 3:10.

$$
\text { Weight loss }(\%)=\frac{\text { Wo }-\mathrm{Wt}}{\text { Wo }} \times 100 \%
$$

Wo $=$ initial weight before immersion and after immersion; $\mathrm{Wt}=$ weight

\section{RESULTS AND DISCUSSION}

There are two methods of synthesis of carboxymethyl chitosan i.e. a reductive alkylation and alkylation directly ${ }^{21}$. In this study, carboxymethyl chitosan was synthesized by direct alkylation methods. In the reductive alkylation method, $-\mathrm{NH}_{2}$ of chitosan unit reacts with the carbonyl group of
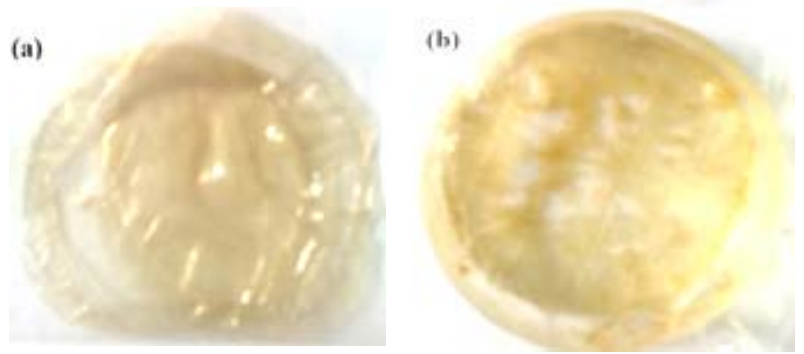

(c)

Fig. 3. Film forming of $1 \mathrm{a}$ chitosan (a), $1 \mathrm{~b}$ chitosan (b) and Carboxymethyl chitosan (c)

Tabel. 1: Effect of chitosan MW to the number of $\mathrm{COOH}$ groups formed

\begin{tabular}{lllll}
\hline $\begin{array}{l}\text { Chitosan } \\
\text { resources }\end{array}$ & $\begin{array}{l}\text { Power } \\
\text { (Watt) }\end{array}$ & $\begin{array}{l}\text { MW } \\
(\mathrm{g} / \mathrm{mol})\end{array}$ & Labeling & $\begin{array}{l}\mathrm{COOH} \\
\text { number }\end{array}$ \\
\hline Reflux & 1035 & 6051 & $1 \mathrm{a}$ & $56,580 \mathrm{cmol} / \mathrm{kg}$ \\
Microwave & 400 & 4255 & $1 \mathrm{~b}$ & $70,000 \mathrm{cmol} / \mathrm{kg}$ \\
Microwave & 560 & 4492 & $1 \mathrm{c}$ & $6,110 \mathrm{cmol} / \mathrm{kg}$ \\
Microwave & 800 & 3794 & $1 \mathrm{~d}$ & $82,950 \mathrm{cmol} / \mathrm{kg}$ \\
\hline
\end{tabular}


peaks at $1700 \mathrm{~cm}^{-1}$ region which is the vibration of a carbonyl group $\mathrm{CO}$, accompanied by increased absorption peaks in the $1000-1150 \mathrm{~cm}^{-1}$ which are the $\mathrm{CO}$ stretching vibration indicates an increase in the ratio of the number of groups than other groups in the molecule or can be said to be an acetyl group $\left(-\mathrm{CH}_{2} \mathrm{COOH}\right)$ has been included in the structure of carboxymethyl chitosan to form chitosan.

The results of $\mathrm{COOH}$ groups are presented in Table 1. The data in Table 1 also shows that the number of the $\mathrm{COOH}$ increases with decreasing the molecular weight of chitosan. The Smaller and more amorphous polymer chitosan are more effective to make $\mathrm{CMC}$. The $\mathrm{COOH}$ property is very important for this film because $\mathrm{COOH}$ group has ability against bacteria. The more $\mathrm{COOH}$ groups formed of this polymer, it is to be expected that the film can protect the skin from infection effectively.

The addition of microwave radiation time will lead to produced lower molecular weight of chitosan ${ }^{22}$. Chitosan and carboxymethyl chitosan with a smaller molecular weight tend to have smaller polymer size ${ }^{23}$. If the size of the polymer decreases the rigidity and steric hindrance also declined. Synthesize of chitosan by microwave radiation tend to form an amorphous solid that is easier to soften by $\mathrm{NaOH}$ into a gel. Consequently, more monomers are activated chitosan becomes nucleophile ready to attack mono chloroacetic acid. The amorphous layer of chitosan will also be more easily penetrated by mono chloroacetic acid, so the reaction can be more effective to produce carboxymethyl substitution on chitosan.
Figure. 3 show the physical properties of chitosan and CMC film. Chitosan film from reflux (a) is strong and rigid while chitosan films from MAOS (b) and CMC films (c) have fragile nature. Strangeness and flexibility of chitosan are needed for the substitution of plastic PVC, while the bio-solubility is the most importance properties for CMC as the active agent. Test of solubility in physiological solution $(1 \% \mathrm{NaCl})$ showed that the CMC films lost $78.56 \%$ it's mass while chitosan film is only $44.59 \%$. This is because the film carboxymethyl chitosan is much more soluble and degraded in physiological solution than chitosan films. Carboxymethyl chitosan has a lot of groups that can form anions (-COO-) and even can also cations $\left(\mathrm{NHx}^{+}\right)$when forming a mixture of $\mathrm{N} / \mathrm{O} / \mathrm{N}, \mathrm{N} /$ $\mathrm{N}, \mathrm{O}$-carboxymethyl chitosan, and thus more easily soluble in physiological solution in which the main components is water. This show that a combination of chitosan films for wound plaster with CMC films as a wound healer active ingredient is suitable for replacing the fabric wound plasters contains silver as an active ingredient.

\section{CONCLUSION}

The lower molecular weight of chitosan is good for the synthesis of carboxymethyl chitosan with a higher amount of $\mathrm{COOH}$ groups. Carboxymethylchitosan film has better bio-solubility than chitosan film that makes these films suitable to be applied as a combination plaster wounds.

\section{ACKNOWLEDGEMENT}

We thank the ministry of higher education of Indonesia (DIKTI) for funding this research via PKM-P program 2012.

\section{REFERENCES}

1. Moore, L.S.P.; Freeman, R.; Gilchrist, M.J.; Gharbi, M.; Brannigan, E.T.; Donaldson, H.; Livermore, D.M.; Holmes, A.H.; J. Antimicrob. Chemother. 2014, 69, 3409-3422.

2. James, R.; Upjohn, L.; Cotta, M.; Luu, S.; Marshall, C.; Buising, K.; Thursky, K.; J. Antimicrob. Chemother. 2015, 26, 1912-1918.

3. Parvez, S.; Rahman, M.; Khan, M.; Khan, M.A.; Islam, M.J.; Ahmed, M.; Rahman, M.F.; Ahmed, B.; Polym. Bull. 2012, 69, 715-731.
4. Yan, X.; Guang, X.; Wu, Z.; Jin, H.; Cha, D.; Carbohydr. Polym. 2011, 83, 1479-1485.

5. Shepherd, R.; Reader, S.; Falshaw, A.; Glycoconjugate Journal. 1997, 14, 535-542.

6. Wang, L.; Li, Q.; Wang, A.; Polym. Bull. 2010 , 65, 961-975.

7. Wang, L.; Chen, X.; Xu, Q.; Zhong, D.; J Mater Sci Mater Med. 2007, 18, 1125-1133.

8. Fan, L.; Wang, L.; Gao, S.; Wu, P.; Li, M.; Xie, W.; Liu, S.; Wang, W.; Carbohydr. Polym. 
2011, 86, 1167-1174.

9. Feng, C.; Chen, X.; Zhang, J.; Sun, G.; Cheng, X.; Wang, Z.; Park, H.; Front. Chem. China. 2011, 6, 31-37.

10. Kong, M.; Guang, X.; Xing, K.; Jin, H.; Int. J. Food Microbiol. 2010, 144, 51-63.

11. Zhao, Z.; Wang, Z.; Wang, S.; Desalination 2002, 144, 35-39.

12. Muzzarelli, R. A. A. Carbohydr. Polym. 2009, 76, 167-182.

13. Hawary, D. L.; Motaleb, M. A.; J radioanal Nucl Chem. 2011.

14. Janvikul, W.; Uppanan, P.; Thavornyutikarn, B.; Prateepasen, R.; Swasdison, S.; J Mater Sci Mater Med. 2007, 18, 943-949.

15. Chen, X.; Wang, Z.; Liu, W.; Park, H.; Biomaterials. 2002, 23, 4609-4614 (2002).

16. Tunney, M. M.; Brady, A. J.; Buchanan, F.;
Newe, C.; Dunne, N. J.; J Mater Sci Mater Med 2008, 19, 1609-1615.

17. Stone, C. A.; Wright, H.; Clarke, T.; Powell, R.; Devaraj, V. S.; Br. J. Plast. Surg. 2000, 53, 601-606.

18. Shuya, H.; Huang, S.; Han, B.; Shao, K.; J. Ocean Univ. China. 2014, 13, 837-838.

19. Sikai, P.; Wanshun, L.; Baoqin, H.; Jing, C.; Minyu, L.; Xuan, Z.; J. Ocean Univ. China. 2011, 10, 369-370.

20. Jannah, N.; Sebri, M.; Anuar, K.; Amin, M. A. T.; OJC. 2017, 33, 628-636.

21. Mourya, V. K.; Inamdar, N. N.; Tiwari, A.; Adv. Mat. Lett. 2010, 1, 11-33.

22. Sahu, A.; Goswami, P.; Bora, U.; J Mater Sci: Mater Med. 2009, 20, 171-175.

23. Tan, Y.; Han, F.; Ma, S.; Yu, W.; Polym. 2011, 84, 1365-1370. 